Для цитирования:

Попова, Т.И. (2019) ОСОБЕННОСТИ ФОРМАТА СОВРЕМЕННОГО ИНТЕРВЬЮ НА ҮОUТUВЕ-КАНАЛЕ // International Scientific-Pedagogical Organization of Philologists “WEST-EAST” (ISPOP) . Scientific Journal WEST-EAST. Vol 1/1 N1

(October, 2019). C. 113-117. doi:

Information about the author: Tatiana Popova -Doctor of Philology, Professor of the Department of Russian as a foreign language and its teaching methods of St Petersburg State University, Russia

e-mail: t.popova@spbu.ru

Сведения об авторе: Татьяна Игоревна Попова - Доктор филологических наук, профессор, профессор кафедры русского языка как иностранного и методики его преподавания Санкт-Петербургского государственного университет, Россия

e-mail: t.popova@spbu.ru

DOI:

\title{
POLYCODE TEXT IN INTERNET COMMUNICATION (BASED ON THE MEDICAL ACCOUNTS INSTAGRAM)
}

\author{
Evgeniya Vladimirovna Volkova \\ Head of Russian Language Testing Center, postgraduate student, \\ Department of Russian Language, School of Core Engineering, \\ National Research Tomsk Polytechnic University \\ (Tomsk, Russia) \\ e-mail: evolkova@tpu.ru
}

The reported study was funded by RFBR according to the research project № 17-29-09132.

\begin{abstract}
The paper deals with the communicative and pragmatic potential of the polycode text in medical Internet communication. The material is media texts of a new type - posts of professional doctors' accounts in the social network Instagram. The choice of material is due to the specifics of the technological tools of the mobile application, as well as the popularity of using the social network for personal and professional communication on the Internet.The processes of construction and perception of different types of polycode texts are analyzed, the ways of complex influence on the mass addressee of language, visual, graphic, audial means in the media text are identified. It is established that the multimedia and interactive features of the social network Instagram allow representatives of the medical community to successfully implement professional Internet communication strategies and effectively influence the target audience through a combination of verbal and non-verbal components in a polycode text.
\end{abstract}

Keywords: polycode text, media text, Internet communication, Instagram, medical communication.

\section{ПОЛИКОДОВЫЙ ТЕКСТ В ИНТЕРНЕТ-КОММУНИКАЦИИ (НА МАТЕРИАЛЕ МЕДИЦИНСКИХ АККАУНТОВ INSTAGRAM)}

\author{
Евгения Владимировна Волкова \\ Заведующий Центром тестирования иностранных граждан, \\ аспирант отделения русского языка Школы базовой инженерной подготовки, \\ Национальный исследовательский Томский политехнический университет \\ (Томск, Россия) \\ e-mail: evolkova@tpu.ru
}

Исследование выполнено при финансовой поддержке РФФИ, проект № 17-29-09132.

\begin{abstract}
Аннотация.В статьерассматривается коммуникативно-прагматическийпотенциал поликодового текста в медицинской интернет-коммуникации. В качестве материала выступилимедиатексты нового типа - посты профессиональных аккаунтов врачей в социальной сети Instagram. Выбор материала обусловлен спецификой технологических инструментов мобильного приложения, а также популярностьюиспользованиясоциальной сети для личного и профессиональногообщения в Интернете. Анализируются процессы конструирования и восприятия поликодовых текстов разного типа, выявляются способы комплексного воздействия языковых, визуальных, графических, аудиальных средств на массового адресата.Устанавливается, что мультимедийные и интерактивные возможности социальной сетиInstagramпозволяют представителям медицинского сообществауспешно реализовать стратегии профессиональной интернет-коммуникации и
\end{abstract}


эффективно воздействовать на целевую аудиторию посредством сочетания вербальных и невербальных компонентов вполикодовом тексте.

Ключевые слова: поликодовый текст, медиатекст, интернет-коммуникация, Instagram, медицинская коммуникация

ВВЕДЕНИЕ. Современные социально-экономические условия клиенто- ориентированности и конкуренции определили активное обращение профессиональных сообществ, в том числе медицинского, к массовой интернет-коммуникации. В соответствии с тенденцией к личной самопрезентации врачи создают профессиональные аккаунты в социальных сетях для общения с массовой аудиторией на темы, связанные с медициной и здоровьем. Научный интерес к новым коммуникативным практикам в профессиональном дискурсе определяет актуальность анализа медицинской коммуникации в глобальной сети.

Профессиональные тексты в интернете создаются по общим законам медиатекстов и обусловлены медиадискурсивными процессами, усиливающими информационное воздействие на массового адресата: медиаконвергентностью, мультимедийностью, трансмедийностью, интерактивностью. Медиатекстфункционирует как «диалектическое единство языковых и медийных признаков, представленное тремя формами медиаречи: словесным текстом, уровнем видеоряда или графического изображения, уровнем звукового сопровождения» (Nesterova 2015: 20), и характеризуется гипертекстуальностью, полижанровостью, поликодовостью.

Объектом данного исследования является поликодовость как онтологическое свойство медиатекста (Medialingvistika v terminakh i ponyatiyakh: slovar-spravochnik 2018: 88). Предметом выступают коммуникативнопрагматические возможностиполикодового текста в медицинской интернет-коммуникации. Цель исследования заключается в выявлении способов воздействия на целевую аудиторию посредством сочетания вербальных и невербальных компонентов в медицинском медиатексте в социальной сети Instagram.Материалом послужилипостыпрофессиональных аккаунтов врачей. Выбор материала обусловлен спецификой соцсети Instagram, предполагающей репрезентацию языковой личности пользователявмедиатекстах, онтологическим свойствомкоторых является семиотическая неоднородность, а также популярностью использования мобильного приложения для личного и профессиональногообщения в Интернете.

ПОЛИКОДОВЫЙТЕКСТВINSTAGRAM. В отечественной лингвистикеотсутствует единый общепринятый термин для обозначения текстов, сочетающих вербальные и невербальные средства.Наряду с терминомполикодовыц̆, разными исследователями предлагаются такие определения, как креолизованныцй, семиотически осложненный, вербально-визуальныйтексти т.д. (там же). В данном исследовании используетсяпонятиеполикодовый тексткак текст, сочетающий «естественный языковой код с кодом иной семиотической системы (изображения, музыка и т.п.)», введенный лингвистами Г.В. Ейгером и В.Л. Юхтом в 1974 году (EjgerandJuht 1974: 107).

Выборопределения обусловлен его неразрывной связью с понятиямимедиаконвергентность $u$ мультимедийность, характеризующимисовременный медиадискурс. Медиаконвергентностькак процесс слияния различных типов массмедиав результате развития интернет-технологийпозволяет преобразовывать «мономедийные информационные продукты в мультимедийные» (Medialingvistika v terminakh i ponyatiyakh: slovar-spravochnik 2018: 43), что в значительной степени определяет современную специфику технического конструирования текста, в котором вербальные, музыкальные, изобразительные компоненты взаимодополняют друг друга и комплексно воздействуют на адресата.

Лингвисты отмечают, что поликодовый текст, как и текст вербальный, обладает основными текстуальными признаками: целостностью и связностью, текстовой модальностью, темпоральностью и локативностью; характеризуется взаимосвязанностью и взаимообусловленностью содержательного плана и формальной стороны, выраженной вербальными, иконическими и паралингвистическими средствами, и таким образом являет собой смысловое, композиционное и функциональное целое (Anisimova, 2003).

Поликодовость сообщений в Instagramопределяется своеобразием мобильного приложения, особенностью которого является размещение пользователями статичного или подвижного визуального компонента (фотография, картинка, видеоролик), который может сопровождаться звуком или музыкой, с последующим добавлением печатного текста. Кроме того, фотосеть предлагает различные мультимедийные функции, позволяющие воздействовать на аудиторию посредством разных каналов восприятия информации:хештег (специальная метка, систематизирующая контент), stories (фото и видео, исчезающие через сутки), «карусель» (размещение в одном посте до десяти фотографий и видеороликов), сервис IGTV (для воспроизведения продолжительных видеороликов).

Анализируя технологические инструменты Instagram, исследователи высоко оценивают возможности социальной сети в области коммуникации и взаимодействия с целевой аудиторией (Geraskina 2018).

АНАЛИЗ МЕДИЦИНСКОГО ПОЛИКОДОВОГО ТЕКСТА. Исследованиеполикодовогомедиатекста в коммуникативно-прагматическом аспекте предполагает учет всех составляющих интернет-коммуникации.При создании текста адресат опираетсяна определенные коммуникативные цели, для реализации которых используетнаиболее эффективные коммуникативные стратегии и тактики, а также мультимедийные возможности современных средств массовой коммуникации.

Представители медицинского сообщества активно используют каналInstagram:специализированные аккаунты - для коммуникации с пациентами и формирования профессионального имиджа, коллективные 
паблики - для неформального общения с коллегами и презентации медицинского сообщества. В фокусе внимания данного исследования находятсямедиатексты, созданные и размещенные врачамив личных профессиональныхаккаунтах.

Значимость эффективной коммуникациив медицинском дискурсе определяется реализациейосновной цели взаимодействияврача и пациента - оказать помощь заболевшему человеку. На разных этапах медицинского общения исследователи выделяют диагностирующую, лечащую и рекомендующую коммуникативные стратегии, воздействующие на поведение человека (Barsukova 2007).«Медицинский дискурс характеризуется высокой степенью суггестивности, врач должен внушать пациенту доверие и формировать установки, способствующие успешному лечению» (Dzaraevaand Rogozhnikova 2014: 48).Вследствие опосредованного и дистантногохарактера общения вИнтернете происходит трансформация коммуникативных стратегий медицинского дискурса. Задачами коммуникации становятсяинформирование ипросвещение массовой аудитории в области медицины и здорового образа жизни. К медицинским добавляются стратегии формирования целевой аудитории, вовлечения в диалог и удержания адресата, обусловленные основной цельюмедиадискурса -воздействие на массовую аудиторию.

Необъятный массив информации в Интернете вынуждает авторов создавать поликодовыетексты, обладающие «высокой информационной емкостью и прагматическим потенциалом - значит, реципиенту требуется меньше времени на схватывание идеи сообщения, а само сообщение значительно сокращается без потери смысла» (Povarnitsyna 2015: 2). В качестве прагматических целей создания поликодовыхмедиатекстоввыделяют функциипривлечения внимания адресата, информативную, побудительную, экспрессивную, а также эстетическую или игровую(Anisimova 2003; Povarnitsyna 2015). Данные функции относятся и к текстам, размещенным на страницах медицинских аккаунтов в Instagram.

Рассмотрим несколько способов воздействия на «массового пациента» на примере реализации коммуникативной модели «вопрос - ответ» посредством сочетания вербальных и невербальных компонентов в медиатекстах. Выбор диалогической конструкции вопроса и ответа в качестве примера обусловлен ядерной позицией данной модели в устном медицинском дискурсе, а также традиционным использованием ее риторических функций в медиадискурсе.

В Instagram данная модель реализует основные стратегии медицинскоймедиакоммуникации: информирование, просвещение, рекомендацию, а также активно используется для формирования целевой аудитории. Интерактивные возможности социальной сети позволяют прогнозировать ожидания массового адресата, врач моделирует предполагаемый вопроспациента и отвечает на него, вовлекая в коммуникацию именно тех пользователей, которые заинтересованы в данном контенте.

Одним из способов оформления модели «вопрос - ответ»в поликодовомтексте является использованиевопросительного предложения (вопроса пациента) или утвердительного предложения (ответа врача на предполагаемый вопрос) в изобразительном элементев качестве заголовкак сообщению. В данном типе медиатекстаизображениеявляется иллюстрацией к основномувербальному тексту испособствует упрощению восприятияинформации адресатом (рис. 1).
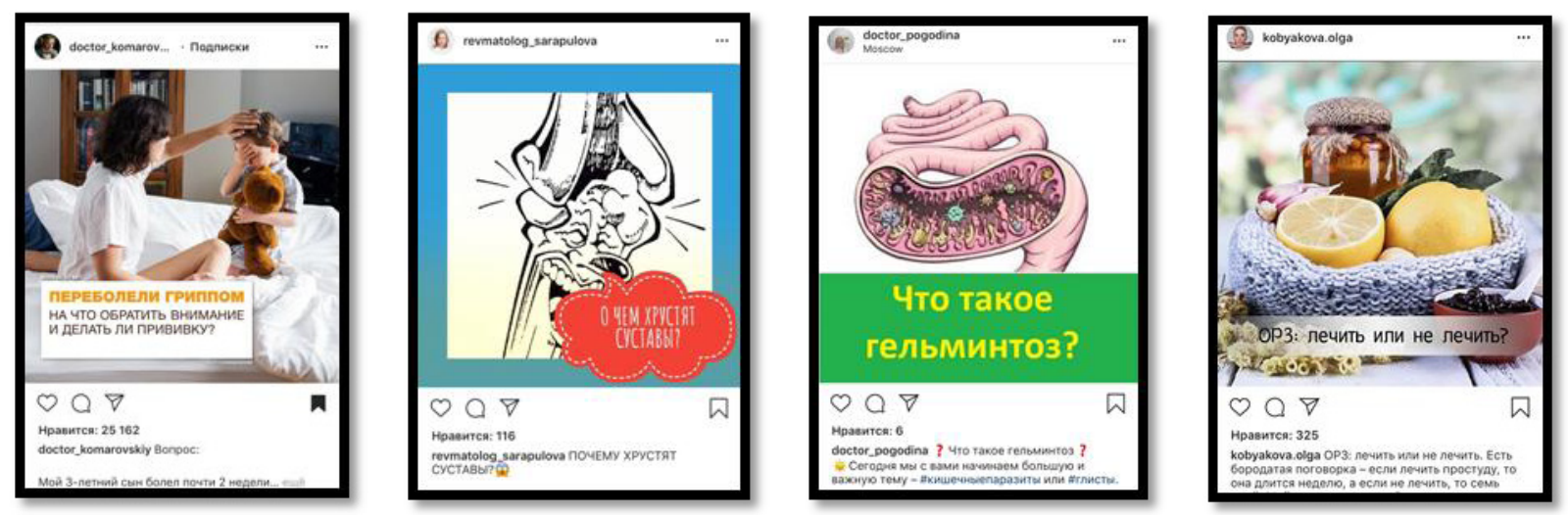

Рис.1. Примеры реализации «вопроса - ответа» в заголовке (Instagram, моб. приложение)

При анализе вербального текста в Instagram отмечаются следующие способы креолизации: использование эмотиконов, фрагментация текста, создание нумерованных или маркированных списков, редупликация или отсутствие знаков препинания, выделение ключевых слов прописными буквами, внедрение хештегов в синтаксические конструкции и т.д.

В связи со спецификой медицинской деятельностиобъектом визуализации часто становятся человеческий организм,части тела и органы.Такиеизображения,как правило, носят метафорический характер и используются с цельюэвфемизации информации, в целом свойственнойобщениюврача и пациента. Вместо реальных 
фотографий человеческого организма для иллюстрации симптомов и последствий заболеваний размещаются рисунки, схемы, изображения неодушевленных объектов. Также рисунокпозволяет продемонстрироватьто, что невозможно увидеть на реальной фотографии,выступая средством наглядности (рис.1).

При создании постов в Instagram медицинские блогеры активно обращаются к популярной тенденции использования игрового элемента в заголовке, представленного выбором двух противоположных ответов на предложенную тему, что стимулирует адресата прочитать текст под изображением (рис. 1).

Следующий способ воспроизведения модели «вопрос-ответ» в поликодовом тексте - это размещение вопроса и ответа непосредственно в визуальной части поста. Изображение (или видео) занимает доминирующую позицию в процессе восприятия текста и берет на себя функцию информационного плаката, вербальный компонент под изображением представляет собой короткий дополняющий или уточняющий комментарий, аможет и вовсе отсутствовать (рис. 2).
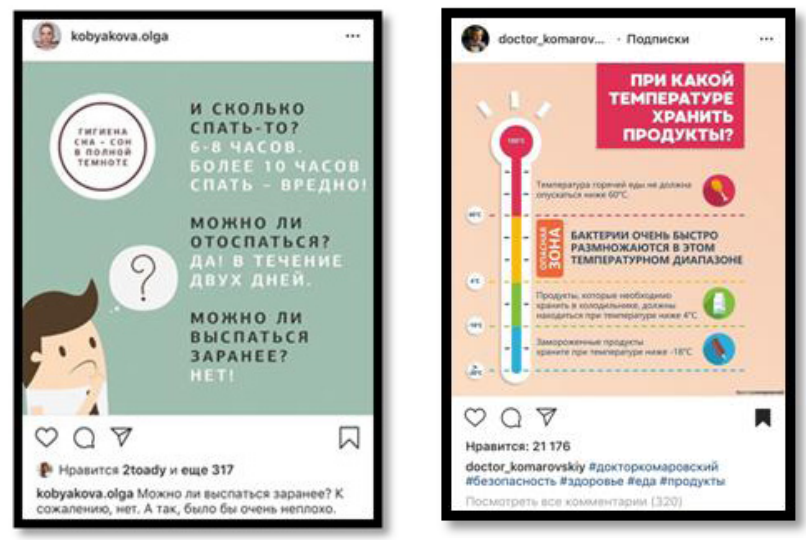

Рис.2. Примеры реализацчии «вопроса - ответа» на информационном плакате (Instagram, моб. приложение)

Тем не менее печатный или устный текст, включенный в визуальный компонент, остается ведущим в процессе реализации стратегий медицинского дискурса и представлен инструкцией, советом, рекомендацией, запретом, а изображение или видео выполняют аттрактивную функцию, усиливая информационное воздействие на массового адресата. Длякреолизации вербального текста используются различные паралингвистические средства: рисунки, графики, таблицы, списки, цветовое выделение, шрифты, цифры и т.д. Информационные плакаты акцентируют внимание на главном, систематизируют информацию и облегчают ее восприятие, а следовательно, экономят время читателя.

С целью сокращения времени восприятия медиатекста и экономии речевых средств инстаблогеры обращаются кфункции карусель: серия последовательных изображений или видеоэлементов, сменяющих друг друга, позволяет разместить большой объем информации в визуальной части поста (рис. 3).
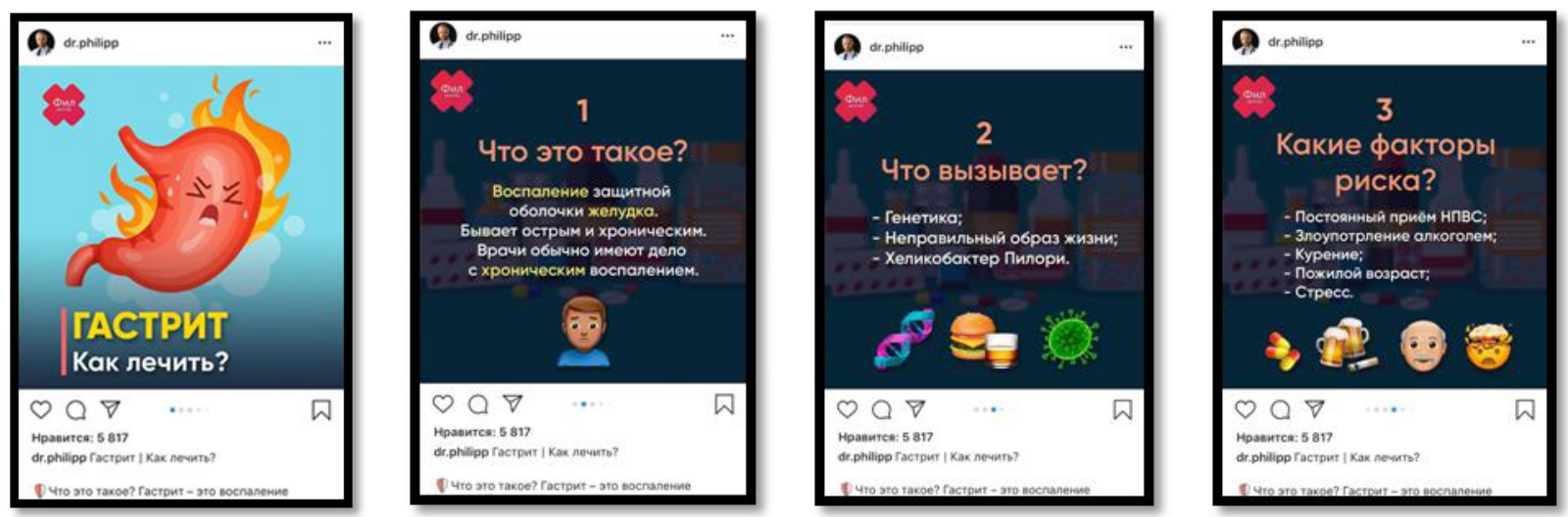

Рис.3. Примеры реализации «вопроса - ответа» в карусели (Instagram, моб. приложение)

Коммуникативная модель «вопрос - ответ»реализуется в постах, визуальным компонентом которых является видеоролик, имитирующий консультацию врача.Особенностью использования видеоэлементов в специализированном профиле является дублирование устной информации в печатном тексте под видео или субтитрами, всплывающим текстом в самом видео. Многоканальность таких медиатекстов предоставляет адресату возможность самостоятельно выбирать удобный способ получения информации. Для подробных устных консультаций используются возможностисервиса IGTV, позволяющего размещать продолжительные видео. 
В связи с интерактивностью социальной сети Instagram модель «вопрос - ответ» используется медицинскими блогерами при созданииимиджевых текстов самопрезентации и презентации медицинского сообщества. Врачи создают специальные посты, в которых предлагают задавать вопросы в комментариях. Также вопрос может быть представленриторическим обращениемавтора к адресату с целью установления контакта и вовлечения в диалог на различные темы.
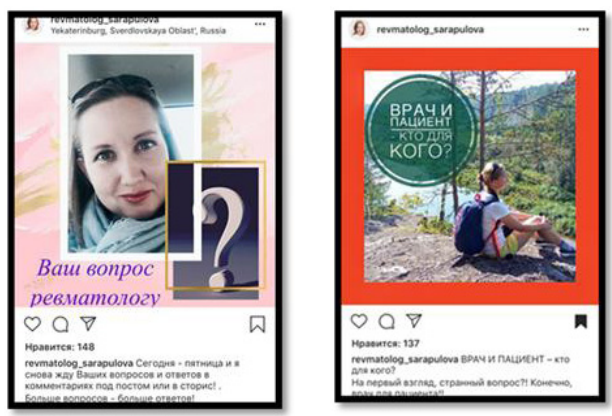

Рис.4. Примеры реализации «вопроса - ответа» в имиджевом тексте (Instagram, моб. приложение)

Такиеполикодовые текстыреализуют стратегию формирования целевой аудитории,в качестве невербального компонента традиционно используется фотографияили видеоролик врача, в создании вербального текста под изображением активное участие принимают подписчики аккаунта (рис. 4).

ЗАКЛЮЧЕНИЕ. В рамках данной статьи представленонесколько способов реализации в поликодовых текстаxInstagramтолько одной коммуникативной модели «вопрос - ответ». Однако данный анализ позволяет сделать следующие выводы, в целом характеризующие комплексное воздействиевизуальных, вербальных и аудиокомпонентовмедиатекстана адресата интернет-коммуникации.

Основным способом информирования и просвещения «массового пациента» по-прежнему остается вербальный компонент сообщения, представленный письменным или устным текстом. Визуальный компонент используется в качестве иллюстрации и систематизации информации.

Оформлениевизуальной части в виде инструкции или руководства к действию посредством графических средств, таблиц, фрагментации, нумерованных или маркированных списков, способствует упрощению восприятия текста и экономии времени и усилий адресата. Дополнительные средства креолизации текста (цветовое выделение, использование эмотиконов, разных шрифтов, музыкального сопровождения и т.п.) выполняютпобудительную, экспрессивную, игровую, эстетическую функциис целью привлечения внимания к специализированному контенту.Многоканальностьвоспроизведения информации в поликодовых текстах предлагает адресату выбор наиболее комфортных для него способоввосприятия.

Таким образом, социальная сеть Instagram предоставляет медицинским блогерам широкий спектр мультимедийных возможностей для создания поликодового текста, позволяющего успешно реализовать стратегии медицинской интернет-коммуникации и эффективно воздействовать на целевую аудиторию.

\section{LIST OF REFERENCES}

Anisimova E.E. (2003) Lingvistika teksta i mezhkulturnaia kommunikatsiia (na materiale kreolizovannykh tekstov) [Text linguistics and cross-cultural communication (on the material of creolized texts)]. Moscow: Akademiya Publ., 128 p.

Barsukova M.I. (2007) Meditsinskiydiskurs: strategiiitaktikirechevogopovedeniyavracha: avtoref. dis. ... kand. filol. nauk. [Medical discourse: strategies and tactics of doctor's speech behavior: abstract of PhD thesis in Philological sciences]. Saratov. $23 \mathrm{p}$.

Dzaraeva N.A., Rogozhnikova R.A. (2014) Strategiiitaktikirechevogopovedeniyavracha [Strategies and tactics of medical staff verbalbehavior]. Vestnik PSPU. Seriya № 1. Psikhologicheskiyeipedagogicheskiyenauki, pp. 47-53.

Ejger G.V., Juht V.L. (1974)K postroenijutipologiitekstov [Construction of text typology].Lingvistikateksta: materialynauch. konf. priMGPIIJaim. M. Toreza.Moscow. Ch. 1 pp. 103-109.

Geraskina M.V. (2018)Instagramkakperspektivnyy instrument dlyareklamnoykampanii v Internete [Instagram perspective tool for internet marketing]. Journal of science and education. no. 12 (48).pp. 83-87.

Medialingvistika v terminakhiponyatiyakh: slovar-spravochnik(2018) [Metalinguistics in terms and concepts: glossary]. Moscow: FLINTA. $440 \mathrm{p}$.

Nesterova N.G. (2015)Sovremennyyradiodiskurs (kommunikativno-pragmaticheskiyaspekt) [Modern radiodiskurs (communicativepragmatic aspect)]. Tomsk: Izd-vo Tom. un-ta. $320 \mathrm{p}$.

Povarnitsyna M.V.(2015) Спецификакреолизованныхтекстоввмассовойинтернет-коммуникации [Creolized text specifics in mass Internet communications]. Universum: Filologiyaiiskusstvovedenie: electronic scientific journal. no. 6 (19).http://7universum.com/ ru/philology/archive/item/2219 [20.04.2019]. 
For citation:

Volkova, E.V. (2019) POLYCODE TEXT IN INTERNET COMMUNICATION (BASED ON THE MEDICAL ACCOUNTS INSTAGRAM). International Scientific-Pedagogical Organization of Philologists “WEST-EAST" (ISPOP). Scientific Journal WEST-EAST. Vol 1/1 N1 (October, 2019). pp. 117-122. doi:

\section{Для цитирования:}

Волкова, Е.В. (2019) ПОЛИКОДОВЫЙ ТЕКСТ В ИНТЕРНЕТ-КОММУНИКАЦИИ (НА МАТЕРИАЛЕ МЕДИЦИНСКИХ

AККАУНТОВ INSTAGRAM)// International Scientific-Pedagogical Organization of Philologists “ WEST-EAST” (ISPOP) .

Scientific Journal WEST-EAST. Vol 1/1 N1 (October, 2019). C. 117-122. doi:

Information about the author: Volkova Evgeniya Vladimirovna - Head of Russian Language Testing Center, postgraduate student, Department of Russian Language, School of Core Engineering,National Research Tomsk Polytechnic University, Tomsk, Russia

e-mail: evolkova@tpu.ru

Сведения об авторе: Волкова Евгения Владимировна - Заведующий Центром тестирования иностранных граждан, аспирант отделения русского языка Школы базовой инженерной подготовки, Национальный исследовательский Томский политехнический университет,Томск, Россия.

e-mail: evolkova@tpu.ru 